\title{
Analysis and Strategy of the Current Situation of Physical Education Curriculum Construction in Higher Education in China
}

\author{
Liang SONG ${ }^{1 \text {, a }}$ \\ ${ }^{1}$ Zhongzhou university, Zhengzhou 450044, Chi na \\ aliangsong@yeah.net
}

\begin{abstract}
Keywords: physical education curriculum, curriculum construction, current situation analysis,
\end{abstract} countermeasures

\begin{abstract}
College sports, as an important part of the school, plays a very important role in cultivating talent. Therefore, how to create a healthy school sports, all-round development of high-quality talent is worth in today's sports workers study. In this paper, through investigation and analysis of the status of reform of physical education in public colleges and universities, a model of development of physical education is put forward.

In the views of the direction of dialectical materialism and historical materialism, this paper analyses the current situation of physical education curriculum construction and reform by means of literature review and comprehensive analysis. It was concluded that the curriculum content is diversifying; the curriculum structure is sensible; the curriculum objective is particularly proposed; the curriculum evaluation tends to be rational.

However, there also exist a certain number of problems, which can be summarized as follows: analysis and solution of problems are lack of reasonable; theoretical studies are much more than empirical studies; teacher's leading role and students as the principal part of the class still remains ambiguous. The paper makes certain useful discussion at the practical level and attempts to provide the theories and practical support for the PE curriculum reforms in higher education in China.
\end{abstract}

\section{Introduction}

Analysis of the current situation of ordinary university sports curriculum teaching in our country and explore the development of curriculums' countermeasures play an important role in implementing the new "national ordinary higher school physical education curriculum teaching means Guide outline (hereinafter referred to as the outline).

At present, emphasis on technology teaching model still occupies a large proportion and overall level of the physical health of college students' rise, at the same time individual indicators declined. According to a new leaf of new students for 1985-2005 three national physical and health monitoring data analysis, the results show that: the overall level of physical health of students progress, while at the same time, there is a decline in physical fitness and athletic ability, lung capacity and vital capacity / body mass index showing a downward trend. The current students in terms of physical health, nearly $40 \%$ of them, show weakness, fatigue, insomnia, inability to concentrate, emotional instability, etc.

From the above analysis, we can see, the physical health, mental health and social resilience of college students in recent years, overall, in a poor condition. The reason for this situation, in addition to some objective factors, is the traditional goal of teaching physical education achieved in a low-leveled status.

\section{The Analysis of College Physical Education Status}

\subsection{Guiding Ideology of the Status of Physical Education Analysis.}

College Physical Education Teaching's guiding question is related to physical Education Reform 
issues. In understanding of this issue, most of the physical education teachers have the same view: "promote the health of students" and "master motor skills" continue to be the guiding ideology of the majority of the current physical education in colleges and universities, respectively, accounted for more than $20 \%$ of the total proportion.

At this point, we can see that it is a pity for college students if they are not able to have life-long physical training awareness after completing the last PE curriculum in their college. Lifelong awareness through the teaching process should be always remembered. In comparison, some teachers think that teaching students a skill should not be the focus of the work while enabling students to establish lifelong awareness is the correct teaching of all about.

Master motor skills are important, but to promote the harmonious development of body and mind of students and lifelong school sports physical consciousness is the purport.

\subsection{Status of Physical Education Organization}

Physical education teachers who each have their own ideas: Some believe it is better focus on sport-specific classes which will help students master the basic techniques and use, laying the foundation for special physical activity; Some tend to form according to the grade that this ease of management and levels of teaching help teachers guide the overall process; In terms of classification in the form of ungraded classes, teachers basically reach a consensus that it is good to develop sports backbones in that high school students can play a lead role in helping and guiding lower grade students in sports and exercise study.

As for the men and women in separate classes in one class, teachers who support the separation believe that this will help smooth the process of physical education, without regard to gender differences.

Those who support "co-ed classes" teachers feel that in the co-ed schools and classes, boys and girls can promote learning since adolescents tend to be active in front of the opposite sex, which is conducive to the common progress of boys and girls.

\section{The Development Strategy of College Physical Education}

Traditional physical education is to master motor skills, single-course system and teaching content, lack of comprehensive and contemporary factors. It is difficult to keep pace with 21st century knowledge-based talent and the pursuit of sports culture.

Therefore, this mode of education cannot meet the new requirements of the times. In face of the new century's knowledge-based talent and overall quality of training, colleges and universities sports teaching reform is imperative.

College physical education goals should be transformed from purely physiological and technical objectives to the natural, social, cultural, economic, and cognitive, emotional, behavioral highly integrated unity.

\subsection{Class Establishment Problems.}

The survey of organizational form of physical education shows that most teachers tend to sub-grade class. There are differences in different grades of students in the physical, psychological and other aspects of knowledge and ability. Teachers have some difficulties in the arrangement of teaching content and teaching arrangements methods.

But there are many advantages in using ungraded classes. Due to physical, psychological knowledge and ability differences in accepting, higher graded students learn relatively fast which will naturally play an exemplary role and they can help lower graded ones who are in a relatively slow movement learn, in turn, they help teachers develop the backbone of the sports team and the idealized helper of teachers.

Of course, lower graded students will strive to improve themselves in order to close the gap. Then a 
harmonious learning atmosphere is formed.

\subsection{Male and Female Arrangement Problem.}

80.9\% of teachers think that men and women separation classes are better than co-ed schools and classes, but $54.3 \%$ of students agreed with separation schools and classes. I believe that according to the characteristics of different sports, some projects can be arranged as co-ed schools and classes, such as: sports dance (originally for both men and women in the project), chess, hiking, Shuttlecock, health classes. Some sports which need to consider gender differences and physical strength separation of men and women should be taken, such as three balls, four-ball, wrestling and track and field, etc.

The former tend to project sort of entertaining. From a sociological perspective, adolescent college students, due to physiological maturity, the awakened consciousness and the opposite sex attractiveness, like the exchanges between the boys and girls, which will help mobilize their initiative. The latter tend to be some technical strength and body strong projects. From fluency of teaching process, teachers will not need consider physical strength and spend more time to take care of girls. So take class separation or co-ed classes according to the actual situation of the universities and sports features.

\subsection{Form of Organization Problem of Physical Abnormalities and the Sick, Disabled and Weak.}

Physical abnormalities and the sick, disabled and weak students are a special group in colleges and universities. These students' physical condition, psychological characteristics and requirements of sports are different from those of the normal students. Therefore, college sports education face a new problem with regards to these special groups.

We should teach not only some of the health knowledge, but also conducive knowledge about physical rehabilitation and the knowledge in sports and some entertainment they are interested and good to fitness, such as chess, health exercises, etc.

\subsection{The Process of Teaching be Student-Oriented}

School should pay attention to the dominant position of students. Students play the main part of understanding the process of teaching and development. The major purpose of physical education should be to stimulate the curiosity of students and the students' classroom learning initiative so that they can enjoy the physical education curriculum, emphasizing freedom, fun to learn.

In the process of teaching physical education curriculum, attention should be paid to resource development. Remember to give the students more involved in and less indoctrination; more autonomy and less intervention; more incentives and less criticism in class.

\section{Conclusion}

University Club is imperative to carry out in physical education. The college sports authorities should give high priority and efforts to create conditions to ensure that the reform of college sports running. Personnel who are on the leadership and management level and participate in physical education reform should seriously study the physical education Club theory to improve their own quality.

And, in turn, the next implementation of physical education club is fully prepared. PE teachers should fully understand the need of reform in physical education and significance of implementing physical education club in public physical education. Before implementing the reform, schools should strive to optimize the structure of teaching staff, improve the stadium, facilities and improve scientific research, in order to increase support for the reform of physical education. 
In the actual operation of physical education reform, the focus should be enhancing the physical fitness of students and sports cultural awareness, physical exercise habits of students and lifelong awareness. Physical education should be targeted for various guidelines and gradually increase their activeness. Then a more scientific and rational model of physical education which adapts to our country's actual situation and characteristics should be explored in order to promote our country's college physical education reform process.

\section{References}

[1] Mao Zhenming. New Vision of Physical Education Reform. Beijing: Beijing Sports University Press, 2004.

[2] Wang Zhengyi, etc. 21st Century Physical Education Reform of University Research, Beijing University of Physical Education, 2002.

[3] Lee Chi. College Physical Education "club model" Preliminary Hubei Sports Science, 2003.

[4] Dong Honggang, Fang Xinpu. On the Reform and Development of PE Education ( $\mathrm{J}$ ) .Sports and Science, 2009, (1): 89-92.

[5] Ding Yuanlian, Zhang Jizhong. Research on the Middle School PE Teachers' Status and Development Strategy in Shan Dong Province. ( J ) . Shandong Institute of Physical Education, 2001, (3): 66-69.

[6] Wang Yongming, etc. Research and Investigation on Shanxi School Sports Situation and Development〔 J $)$.Sports Science, 2004, (9): 78-80.

[7] Zhao Yiping. Huaibei City, Nine-Year Compulsory School Sports Material Conditions Investigation and Analysis〔 J〕.Si Chuan Sports Science， 2003，(1): 71-72. 